\title{
Effects of carbonaceous materials and particle size on oral and inhalation bioaccessibility of PAHs and OPEs in airborne particles
}

\section{Yuan Zeng}

South China Normal University

shejun Chen ( $\square$ shejun.chen@m.scnu.edu.cn )

South China Normal University https://orcid.org/0000-0002-7660-739X

\section{Yun Fan}

Guangzhou Institute of Geochemistry

\section{Qiqi Li}

Guangzhou Institute of Geochemistry

\section{Yufeng Guan}

South China Normal University

\section{Bixian Mai}

Guangzhou Institute of Geochemistry

\section{Research Article}

Keywords: Hydrophobic organic contaminants (HOCs), PM2.5, In vitro, Organic carbon (OC), Elemental carbon (EC)

Posted Date: April 5th, 2021

DOl: https://doi.org/10.21203/rs.3.rs-266917/v1

License: (c) (i) This work is licensed under a Creative Commons Attribution 4.0 International License. Read Full License

Version of Record: A version of this preprint was published at Environmental Science and Pollution Research on June 29th, 2021. See the published version at https://doi.org/10.1007/s11356-021-14848-9. 


\section{Abstract}

Bioavailability of environmental contaminants is attracting considerable scientific attention due to growing awareness of its importance for risk assessment. In this study, potential factors governing bioaccessibility of airborne particles-bound polycyclic aromatic hydrocarbons (PAHs) and organophosphorus esters (OPEs) in stimulated gastrointestinal and respiratory tracts were elucidated. Particle concentrations of PAHs and OPEs at the eight sites were $2.4-32.3 \mathrm{ng} / \mathrm{m}^{3}$ and $1.6-19.9 \mathrm{ng} / \mathrm{m}^{3}$, respectively. In fine particles (with aerodynamic diameter less than $2.5 \mu \mathrm{m}$ ), 4- to 6-ring PAHs were more strongly correlated with organic carbon (OC) than elemental carbon (EC); while 3- and 4-ring PAHs in coarse particles $(2.5-10 \mu \mathrm{m})$ tended to associate with EC. OPEs mostly showed significant correlations with $\mathrm{EC}$ in both fine and coarse particles. $\mathrm{OC}$ and $\mathrm{EC}$ exerted a significantly restraining effect on the oral and inhalation bioaccessibility of most HOCs in fine particles due to sorption of HOC molecules to these components. Furthermore, the effects varied, which could depend either on the emission sources (for oral bioaccessibility of PAHs) or the physicochemical properties of HOCs (for bioaccessibility of OPEs and inhalation bioaccessibility of PAHs). Linear regression indicated that EC should play a more important role in the inhalation bioaccessibility than the oral bioaccessibility. Particle size of airborne particles is a relatively less significant factor determining the bioaccessibility.

\section{Introduction}

Atmospheric particulate matter (PM) is a complex mixture of solid and liquid particles containing various chemicals (Marcoccia et al. 2017). Fine particles with aerodynamic diameter less than $2.5 \mu \mathrm{m}\left(\mathrm{PM}_{2.5}\right)$ are thought to pose the greatest threat to global public health as the particles can diffuse deep into the lung (Kim et al. 2015; Rajagopalan et al. 2018). In contrast, larger particles inhaled can deposit in the extrathoracic and bronchial region and can transfer into the digestive tract by mechanical clearance and swallowing (Guney et al. 2016). Airborne particles can also adhere to various surfaces or food and are ingested by people. In addition to particle size, particle composition can have a significant influence (Kim et al. 2015). Hydrophobic organic compounds (HOCs) are significant components of PM, which can be derived from various sources (e.g., vehicle exhaust, manufacture, cigarette smoke, and indoor emissions) that are closely associated with human exposure (Guo et al. 2019; Salgueiro Gonzalez et al. 2015; Wang et al. 2012). Studies have revealed that exposure to HOCs in ambient air can lead to adverse effects on human health (Kao et al. 2019; Peterson et al. 2015).

Bioaccessibility is the fraction of a compound that is released from its matrix, becoming available for absorption by an organism (Juhasz et al. 2016; Yu et al. 2018). There is a growing interest in bioaccessibility of environmental contaminants due to the growing awareness of its importance for risk assessment calculation (Cui et al. 2016; Gao et al. 2019; He et al. 2016). The physicochemical properties (e.g., hydrophobicity) of a HOC is a pivotal factor controlling its bioaccessibility (Kademoglou et al. 2018; Wang et al. 2013b). For a specific HOC, the nature of the matrix and its affinity for this compound may play a significant role in the bioaccessibility. It has been demonstrated that carbonaceous materials of soil and sediment are principal factors governing the bioaccessibility of HOCs in the matrices (Duan et al. 
2014; Ruby et al. 2016; Werner et al. 2010) due to the sorption of HOCs to carbonaceous materials, which can be broadly described as an absorption or partitioning into natural organic matter (NOM) and an adsorption onto black carbon (BC) (Ruby et al. 2016). A recent study also found that OM content significantly determine the bioaccessibility of polychlorinated biphenyls in house dust (Shen et al. 2019). Particle size of soil and indoor dust could also be a factor influencing bioaccessibility as indicated in a number of studies. Nevertheless, the observed effects were not consistent (positive or negative) (Siciliano et al. 2010; Wang et al. 2013a; Yu et al. 2013).

As comparison, few efforts have been made for bioaccessibility in airborne particles (Huang et al. 2018; Li et al. 2019b). It is not clear whether and how the bioaccessibility of PM-bound HOCs would be affected by particle properties, which may substantially differ from those of soil and settled dust (e.g., composition and particle size). In the present study, fine and coarse PM from various potential emission sources in a megacity in South China were collected and analyzed for two classes of HOCs, polycyclic aromatic hydrocarbons (PAHs) and organophosphorus esters (OPEs). These two classes pollutants both are ubiquitous and at significant concentrations in the environment (Castro-Jimenez et al. 2016; Li et al. 2019a; Polachova et al. 2020), whereas they likely have quite different emission mechanisms (i.e., potentially different affinity to the particles). PAHs are predominantly combustion-derived; while OPEs are a class of widely used flame retardants and plasticizers, and may be released from a variety of sources (Wang et al. 2020). PAHs are well-known carcinogenic substances. OPEs are chemicals of emerging concern, which have been found associated with asthma and allergic disease on children (Doherty et al. 2019). One aim is to investigate the air contamination of PAHs and OPEs and the PM compositions associated with these emission sources. Oral and inhalation bioaccessibility of these particle-bound PAHs and OPEs were assessed by in vitro models. The primary objective is to elucidate the influence of the properties of the airborne particles (specifically carbonaceous materials and particle size) on the bioaccessibility of HOCs.

\section{Materials And Methods}

\section{Sample collection}

Samples were collected in winter at eight sites in the city (Guangzhou). Six sites are in close proximity to specific emission sources, including a petrochemical plant (PCP), a municipal solid waste incineration plant (MSWI), a municipal waste water treatment plant (WWTP), an industrial park (IND), a furniture manufactory (FM), and a traffic site. The other two sites are a residential zone in the downtown area and a suburban site in the college town. In the downtown and suburban site, samples in spring, summer, and fall were also obtained, respectively. This sampling design potentially maximized the differences in the properties of the particles. Size-segregated particles, fine particles $(<2.5 \mu \mathrm{m})$ and coarse particles $(2.5-10$ $\mu \mathrm{m}$ ) were collected using a middle-volume cascade impactor (HY-100D, Qingdao, China) operated at 100 $\mathrm{L} / \mathrm{min}$, which was deployed on a building rooftop (approximately $10 \mathrm{~m}$ above ground level). At each sampling event, the samples were collected in 10-consecutive days (two days for each).

\section{Bioaccessible extraction}


Coarse particles were tested only for oral bioaccessiblity, while fine particles, which were split equally into two parts, were applied for oral and inhalation bioaccessibility, respectively. The particle-loaded filters of each sampling event were grouped equally into two samples (five days for each). The procedures for in vitro bioaccessibility assays have been given in detail elsewhere (Zeng et al. 2019) and in Supplementary Information. Briefly, particles ( $50 \mathrm{mg}$ ) loaded filters were cut into pieces, immerged into 8-mL artificial saliva in a $500-\mathrm{mL}$ flask, and shaken for $5 \mathrm{~s}$. After simulated gastric fluid $(100 \mathrm{~mL})$ was added, the mixture was filled with nitrogen, sealed, and shaken (at a rate of $90 \mathrm{rpm}$ ) in an incubator at $37^{\circ} \mathrm{C}$ for $2 \mathrm{~h}$. Same volume of intestinal fluid was then added, and the mixture was incubated for $5 \mathrm{~h}$. For inhalation bioaccessibility, filters (particles) were shaken $(50 \mathrm{rpm})$ and incubated with lung fluid (Gamble's solution, $70 \mathrm{~mL}$ ) in a 250 -mL flask for 10 min every $4 \mathrm{~h}$, continuing for 1 day.

\section{Chemical analysis and quality control}

Detailed information is also given in Supplementary Information. After incubation, simulated fluids of the oral and inhalation bioaccessibility assays were filtered through filters to separate the solution and particle phrases. The aqueous solution was treated using liquid-liquid extraction method for HOC analysis, after being spiked with surrogate standards. The extracts were then purified with a solid-phase extraction cartridge (Supelclean ENVI Florisil, $3 \mathrm{~mL}, 500 \mathrm{mg}$ ). The solid phase was freeze-dried and Soxhlet extracted with a mixture of acetone/hexane (1:1). Subsequent purification for the extracts followed that for the aqueous solution. Target HOCs (including 15 PAHs and 8 OPEs) were analyzed using an Agilent 7890 gas chromatograph coupled to an Agilent 5975 mass spectrometer (GC-MS) equipped with a DB-5MS capillary column (30 $\mathrm{m} \times 250 \mu \mathrm{m} \times 0.25 \mu \mathrm{m}$ film thickness; J\&W Scientific, CA). Organic carbon $(\mathrm{OC})$ and element carbon $(\mathrm{EC})$ in PM were also determined. A punch of each filter (1.5 $\mathrm{cm}^{2}$ ) was taken prior to the bioaccessibility assays, OC and EC contents were analyzed using an OC/EC aerosol analyzer (Model 4L; Sumset Laboratory Inc., OR, US). The detailed analytical procedures and instrumental parameters of GC-MS and OC/EC analyzer employed are described in Supplementary Information. Bioaccessibility of a $\mathrm{HOC}(\%)$ was the percentage of the mass in the dissolved simulated fluids relative to the total mass (fluid + residual particles).

Procedural blanks were run with each batch of samples $(n=16)$, and only trace amounts were found in blanks for some compounds ( $<3 \%$ of their amounts in most sample extracts), and the results were blankcorrected accordingly. Recoveries of surrogated standards (mean \pm standard deviation) ranged from $74.69 \pm 10.40 \%$ to $102 \pm 13.7 \%$ for PAHs, and from $64.6 \pm 14.0 \%$ to $88.7 \pm 12.3 \%$ for OPEs. Reported concentrations were surrogate-recovery corrected.

\section{Results And Discussion}

\section{Spatial and temporal concentrations and compositions}

Similar spatial distributions of fine and coarse PM concentrations at the sampling sites were found, with average total concentrations ranging from 51.4 to $560 \mu \mathrm{g} / \mathrm{m}^{3}$ in winter. PCP had the highest PM concentrations $\left(346 \pm 150 \mu \mathrm{g} / \mathrm{m}^{3}\right)$, followed by the suburban site $\left(171 \pm 95 \mu \mathrm{g} / \mathrm{m}^{3}\right)$, and the lowest 
concentrations were surprisingly found at the traffic site (Fig. S1). The concentrations at other sites (121 $\pm 62 \mu \mathrm{g} / \mathrm{m}^{3}$ ) varied less. Only the average concentrations of $\mathrm{PM}_{2.5}$ at PCP and suburban sites exceeded the China air quality guideline $\left(75 \mu \mathrm{g} / \mathrm{m}^{3}\right)$. Seasonal variations of fine and coarse PM concentrations at the suburban site were similar but not at the residential site, and their concentrations in winter and spring were higher than those in fall and summer at both the sites.

Concentrations of PAHs and OPEs in PM were $2.4-32.3 \mathrm{ng} / \mathrm{m}^{3}$ and $1.6-19.9 \mathrm{ng} / \mathrm{m}^{3}$ respectively (Fig. 1). The highest concentrations of both PAHs and OPEs were found at the PCP site, and concentrations at the traffic and FM sites were consistently lowest. The concentrations at the PCP and traffic sites corresponded to the PM levels at the two sites; while the low OPE concentrations at the FM site indicated the furniture manufacturing processes were not a significant source of these chemicals, even though some OPFRs are used in furniture (Hou et al. 2016). Higher concentrations of PAHs were also observed at the WWTP site $\left(26.3 \mathrm{ng} / \mathrm{m}^{3}\right)$ suggesting WWTP may be an emission sources of these pollutants to the ambient air, which was also found in a previous study (Sun et al. 2018). At the suburban and residential sites, concentrations of OPEs displayed a similar seasonal pattern, following an order of summer $>$ winter $>$ fall > spring. Seasonal patterns of PAHs at the two sites were also similar, with remarkably higher concentrations occurring in winter. The result indicated similar factors (e.g., emission sources and meteorological conditions) generally influencing the concentrations of OPEs and PAHs in the air that is less affected by point sources in this city.

$\mathrm{OC}$ contents (i.e., mass fractions) in fine particles were highly variable in space and throughout the year (with means of $85.9-256 \mathrm{mg} / \mathrm{g}$ ), whereas its fractions in coarse particles varied relatively less (with means of $177-411 \mathrm{mg} / \mathrm{g}$ ) (Fig. S2). This differed from the PM levles at these sites. Lower OC fractions in PM were found at the FM, PCP, and MSWI sites as well as in spring and summer. EC contents in both fine and coarse PM varied greatly with means of $0.92-45.6 \mathrm{mg} / \mathrm{g}$, and were also lower at the the FM and MSWI sites as well as in spring and summer. The percentage particle-size distributions of OC and EC (Fig. S2) showed that OC was present in greater or comparable proportions in coarse particles $(45 \%-73 \%$, except for a few sites), while EC was more associated with fine particles (47\%-97\%). This was in line with the fact that EC is emitted from incomplete combustion processes as fine particles (Samara et al. 2014). We observed opposite seasonal trends for the percentage particle-size distributions of OC and EC. Specifically, more OC was present in fine particles in fall and winter, while more EC was present in fine particles in spring and summer. It is not clear whether this is a result of changes in sources or in meterological factors.

Mass-normalized concentrations of HOCs in the PM are shown in Fig. S3 (and Table S1 in detail). The concentrations of PAHs (11.7-115 $\mu \mathrm{g} / \mathrm{g})$ and OPEs (8.0-35.8 $\mu \mathrm{g} / \mathrm{g})$ in coarse particles were substantially low compared with those in fine particles $(37.2-296 \mu \mathrm{g} / \mathrm{g}$ for PAHs and $12.7-113 \mu \mathrm{g} / \mathrm{g}$ for OPEs). PAH and OPE concentrations showed different spatial and temporal distributions; whereas a similar distribution in the fine and coarse fractions existed for OPE concentrations. PAHs and OPEs were predominantly associated with fine particles in this city, accounting for $85.3 \pm 7.9 \%$ and $79.4 \pm 6.8 \%$, 
respectively (Fig. S3). The proportions were apparently higher than those of OC and EC indicating these compounds are more preferentially bound to fine particles than the carbonaceous components.

Considering the sorption of HOCs to $\mathrm{OC}$ and EC of the particles, correlations between their contents were analyzed. In fine particles, although most of PAHs (mainly 4- to 6-ring compounds) had significantly positive correlations with EC ( $r=0.384-0.509, p<0.05$; Spearman Correlation analysis), stronger associations with OC $(r=0.396-0.720, p<0.04)$ were found (Table S2). This result suggests a primary absorption of PAHs into the OM of fine particles (Lohmann and Lammel 2004). There were also significant correlations between PAHs (3- and 4-ring compounds) with OC $(r=0.386-0.577, p<0.04)$ and EC $(r=0.399-0.851, p<0.04)$ in coarse particles. Nevertheless, the correlations were more significant for EC than OC, suggesting a dominant adsorption to BC (Lohmann and Lammel 2004). For OPEs, most of OPEs showed significant correlations with EC $(r=0.384-0.821, p<0.05)$ in both fine and coarse particles, implying adsorption onto BC. Mechanism for this contrasting partitioning behaviors of these HOCs in fine particles cannot be given at present. It is possible that $\mathrm{BC}$ domains (surface and nanopores) of particles are occupied preferentially by OPE molecules, which influenced further sorption of PAHs on BC. This competition does not occur in coarse particles containing lower concentrations of PAHs and OPEs. It is noteworthy that the associations of HOCs with $\mathrm{OC}$ and EC were likely not owing to inherent bind to the carbonaceous materials during emission, as PAHs and EC are both from combustion sources and OPEs typically are not combustion-derived.

\section{Oral bioaccessibility and influencing factors}

Overall, bioaccessibility values of OPEs $(58 \pm 29 \%)$ were significantly higher than those of PAHs ( $36 \pm$ $21 \%$ ) (Fig. 2). For PAHs, bioaccessibility values of $3-4$ rings $(37 \%-46 \%)$ were slightly higher than $5-6$ rings $(25 \%-41 \%)$, possibly due to the higher octanol-water partition coefficients $\left(K_{0 w}\right)$ of high-ring compounds. For OPEs, the chlorinated compounds, which are less hydrophobic, had higher bioaccessibility (78-88\%) than phenyl- and alkyl-OPEs (40\%-74\%) (Table S3).

Correlation analysis conducted for the bioaccessibility and contents of $\mathrm{OC}$ and $\mathrm{EC}$ showed that these carbonaceous components of fine particles have a clearly negative effect on the bioaccessibility of HOCs. For PAHs, bioaccessibility values of 5 and 6-ring PAHs were significantly correlated with OC and EC contents (Table 1). Bioaccessibility of OPEs in fine particles was also significantly affected by OC and EC, with exception of tris-(2-chloroexyl) phosphate (TCEP), tris-(1-chloro-2-propyl) phosphate (TCIPP), and tributyl phosphate (TNBP) that are less hydrophobic. In coarse particles, the influence of both OC and EC on bioaccessibility was less noticeable compared to fine particles, and correlations were observed only for a few HOCs. The coarse particles had significantly higher contents of OC than fine particles. Presumably, there may be other factors influencing the bioaccessibility in coarse particles. Surprisingly, correlations for coarse particles were found between EC and several relatively hydrophilic OPEs (TCEP, TCIPP, and TNBP). A reasonable explanation is not available for this, and the result needs to be confirmed by more data. 
Table 1

Correlation coefficients ( $r$ ) between bioaccessibility of HOCs (\%) and contents of OC and EC $(\mathrm{mg} / \mathrm{g})$ in atmospheric particles $^{a}$

\begin{tabular}{|c|c|c|c|c|c|c|}
\hline \multirow[t]{2}{*}{ Compound } & \multicolumn{2}{|c|}{ Fine particle (oral) } & \multicolumn{2}{|c|}{ Coarse particle (oral) } & \multicolumn{2}{|c|}{ Fine particle (inhalation) } \\
\hline & $\mathrm{OC}$ & EC & $\mathrm{OC}$ & EC & OC & EC \\
\hline ACY & -0.166 & -0.128 & 0.128 & 0.079 & -0.190 & $-0.531 * \star$ \\
\hline PHE & -0.168 & -0.144 & -0.266 & 0.182 & $-0.522^{\star \star}$ & $-0.845^{\star \star}$ \\
\hline ANT & -0.064 & -0.114 & -0.368 & 0.028 & $-0.567 * \star$ & $-0.857 * \star$ \\
\hline FLA & -0.344 & -0.319 & -0.240 & 0.073 & $-0.725^{\star \star}$ & $-0.806^{\star \star}$ \\
\hline PYR & -0.313 & -0.309 & -0.085 & 0.159 & $-0.744^{\star \star}$ & $-0.799 \star \star$ \\
\hline $\mathrm{BaA}$ & $-0.393^{*}$ & -0.235 & -0.268 & -0.136 & $-0.719 \star \star$ & $-0.597 \star \star$ \\
\hline $\mathrm{CHR}$ & $-0.490 *$ & $-0.512^{\star \star}$ & $-0.443^{\star}$ & -0.175 & $-0.762^{\star \star}$ & $-0.702^{\star \star}$ \\
\hline $\mathrm{BbF}$ & $-0.541 * \star$ & $-0.538 * \star$ & $-0.466^{\star}$ & -0.215 & $-0.512^{\star \star}$ & $-0.400 * \star$ \\
\hline $\mathrm{BkF}$ & $-0.565^{\star \star}$ & $-0.568 * \star$ & $-0.469 *$ & -0.285 & $-0.565^{\star \star}$ & $-0.552^{\star \star}$ \\
\hline $\mathrm{BeP}$ & $-0.538 * \star$ & $-0.479 *$ & $-0.443^{\star}$ & -0.149 & $-0.588 * \star$ & $-0.561 * \star$ \\
\hline $\mathrm{BaP}$ & $-0.711 * \star$ & -0.668 ** & -0.189 & 0.004 & $-0.635^{\star \star}$ & $-0.517 * \star$ \\
\hline PER & $-0.593^{\star *}$ & -0.568 ** & 0.052 & 0.298 & $-0.650 * \star$ & -0.634 *ᄎ \\
\hline IcdP & $-0.638 * \star$ & $-0.651^{\star \star}$ & -0.212 & 0.010 & -0.285 & 0.027 \\
\hline DahA & -0.375 & -0.313 & -0.366 & -0.011 & -0.310 & 0.046 \\
\hline BghiP & $-0.598 * \star$ & $-0.592^{\star \star}$ & -0.144 & 0.078 & -0.311 & -0.021 \\
\hline TNBP & -0.319 & 0.004 & -0.028 & $-0.572 * \star$ & -0.167 & -0.167 \\
\hline TCEP & -0.322 & 0.087 & -0.125 & $-0.447 *$ & 0.292 & $0.693^{\star \star}$ \\
\hline TCIPP & -0.218 & 0.007 & 0.115 & $-0.602 * \star$ & -0.078 & -0.061 \\
\hline TDCIPP & $-0.503^{\star *}$ & -0.103 & -0.054 & -0.316 & -0.553 ** & $-0.513^{\star \star}$ \\
\hline TPHP & $-0.643^{\star *}$ & $-0.456^{\star}$ & -0.312 & -0.334 & $-0.813^{\star \star}$ & 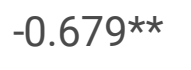 \\
\hline EHDPP & $-0.506^{\star *}$ & -0.261 & -0.209 & -0.228 & $-0.658 * \star$ & $-0.614^{\star \star}$ \\
\hline TEHP & $-0.711^{\star *}$ & $-0.519 *$ & -0.203 & -0.016 & -0.276 & -0.369 \\
\hline TMPP & $-0.682^{\star \star}$ & $-0.579 \star \star$ & -0.271 & -0.349 & $-0.691^{\star \star}$ & $-0.614^{\star \star}$ \\
\hline
\end{tabular}




\begin{tabular}{|c|c|c|c|c|c|c|}
\hline \multirow[t]{2}{*}{ Compound } & \multicolumn{2}{|c|}{ Fine particle (oral) } & \multicolumn{2}{|c|}{ Coarse particle (oral) } & \multicolumn{2}{|c|}{ Fine particle (inhalation) } \\
\hline & OC & EC & OC & $\mathrm{EC}$ & $\mathrm{OC}$ & EC \\
\hline
\end{tabular}

Many studies have demonstrated that $\mathrm{OC}$ and $\mathrm{BC}$ can substantially reduce bioaccessibility/bioavailability in soil and sediment for PAHs (and in fewer cases for other HOCs) (Duan et al. 2014; Oleszczuk et al. 2017; Ruby et al. 2016; Semple et al. 2013; Werner et al. 2010). A recent study by Shen et al. found that OC content significantly influence the bioaccessibility of polychlorinated biphenyls in house dust (Shen et al. 2019). The effects of carbonaceous materials on oral bioaccessibility of HOCs in airborne coarse particles was distinct from that typically found for soil and sediment. The deficient BC in coarse particles may be an explanation. In addition, airborne particles are subject to much less extent of aging or weathering (commonly several days) compared with sediment, soil, and dust (possibly years), an important process influencing the absorption of HOCs in particles (Ruby et al. 2016), which could result in relatively weak $\mathrm{HOC}$ absorption into $\mathrm{OM}$.

We found that PAHs (chrysene, the benzofluoranthenes, the benzopyrenes, perylene, indeno[1,2,3cd]pyrene, dibenzo[a,h]anthracene, and benzo[g,h,i]perylene) that are dominantly derived from gasoline and diesel emissions (Sofowote et al. 2008) were noticeably influenced by both OC and EC in fine particles; while PAHs (such as acenaphthylene, phenanthrene, anthracene, fluoranthene, pyrene, and benzo[a]anthracene) that are related to coal combustion sources (Wang et al. 2015) were less influenced. The results indicated that the effects of carbonaceous materials for PAHs in fine particles are highly associated with their emission sources rather than their physicochemical properties. This finding was consistent with a previous study which indicated that petrogenic PAHs are more bioavailable than pyrogenic PAHs in sediment and the bioavailability was to some extent independent of PAH $K_{\text {Ow }}$ (Thorsen et al. 2004). In contrast, the effects for OPEs in fine particles were closely related to their physicochemical properties (hydrophobicity). Furthermore, the effects of these carbonaceous materials on bioaccessiblity were not dependent on the associations between the $\mathrm{HOC}$ concentrations and $\mathrm{OC}$ or EC in contents in PM.

Bioaccessibility values in fine particles were significantly higher from those in coarse particles for some HOCs, with an overall difference of $8 \%(p<0.02)$. It should be note that there were also significant differences in the $\mathrm{OC}$ and $\mathrm{EC}$ contents between the fine and coarse particles. The $\mathrm{OC}$ and $\mathrm{EC}$ contents in fine particles were on average $70 \mathrm{mg} / \mathrm{g}$ lower and $4 \mathrm{mg} / \mathrm{g}$ higher than those in coarse particles of the present study, respectively. It is possible that the bioaccessibility difference between fine and coarse particles is a combined effect of carbonaceous materials and particle size. Linear regression of the bioaccessibility and OC/EC contents in fine particles was conducted to roughly assess this influence (Table S4). We estimated that a decrease in OC content $(70 \mathrm{mg} / \mathrm{g}$ ) and an increase in EC content (4 
$\mathrm{mg} / \mathrm{g})$ in fine particles will result in an increase of $4 \%-17 \%($ mean $=11 \%)$ and a decrease of $4 \%-8 \%$ (mean $=6 \%$ ) in the HOC bioaccessibility, that is, an increase of $5 \%$ for the effect of carbonaceous materials. This means that the particle size would explain the rest difference ( $3 \%$, absolute value). Previous studies have found significant influence of particle size on oral bioaccessibility of HOCs and heavy metals in soil and indoor dust (La Guardia and Hale 2015; Wang et al. 2013a; Yu et al. 2013). Liu et al. found that higher bioaccessibility of PAHs in large particle-size indoor dust (200-2000 $\mu \mathrm{m})$ than in smaller particles (Liu et al. 2018). Some studies observed oral bioaccessibility increases with decreasing particle size, and attributed this to the higher specific surface areas of small particles (Raffy et al. 2018; Wang et al. 2013b). To our knowledge, there is only one study to date describing the effect of particle-size of airborne particles, which found a generally increasing trend of bioaccessibility of trace elementals with decreasing particle size (Niu et al. 2010). However, the influence of carbonaceous materials in that study was not addressed. A recent study found bioaccessibility of PAHs in smoke of plastics burning increased with increasing particle size, but OC play a minor role (Xie et al, 2018). Possible explanations for the relatively weak effects particle size in this study are the much lesser extent of aging or weathering of airborne particles as well as the smaller sizes atmospheric particles $(<10 \mu \mathrm{m})$ than dust and soil (40-2000 $\mu \mathrm{m})$ (He et al. 2018).

\section{Inhalation bioaccessibility and influencing factors}

Generally, relative inhalation bioaccessibility of HOCs was significantly lower than the oral route, except for several OPEs showing comparable bioaccessibility (Fig. 1 and Table S5). PAH bioaccessible fractions ranged from 2-29\% and generally decreased with increasing molecular weight. TNBP, triphenyl phosphate (TPHP), and chlorinated OPEs showed substantially higher bioaccessibility $(51 \%-88 \%)$ than other OPEs (approximately 10\%). PAH bioaccessibility values in the present study are consistent with those (with medians of $10 \%-20 \%$ ) in $\mathrm{PM}_{2.5}$ in a recent study (Li et al. 2019b). Liu et al. (2019) recently observed considerably low bioaccessibility $(<0.75 \%)$ of PAHs in biochar. Inhalation bioaccessibility of phthalate esters in house dust (Kademoglou et al. 2018) was similar to that for OPEs in this study.

Bioaccessibility of PAHs was significantly associated with OC and EC in fine particles $(r=-0.399$ to $-0.856, p<0.01)$, except for a few high molecular weight compounds. There was also a tendency that the associations were more noticeable for compounds with low molecular weights or $K_{\mathrm{OW}}$ values (Table 1 ). Previous studies have found decreasing oral bioaccessibility of HOCs with increasing $K_{\mathrm{OW}}$ (Fang and Stapleton 2014; Kang et al. 2012; Zhang et al. 2015). In the present study, the result indicated the effects of $\mathrm{OC}$ and $\mathrm{EC}$ on bioaccessibility in lung fluid depend on these physicochemical properties, differing from that for oral bioaccessibility (emission source dependent). Similar correlation was also found for the inhalation bioaccessibility of phthalate esters in house dust as shown in a recent study (Kademoglou et al. 2018). Significant associations with OC and EC were also found for the hydrophobic OPEs (Table 1). Likewise, linear regression between the bioaccessibility and OC/EC content was conducted for inhalation scenario. For a reasonable field-based decrease of $100 \mathrm{mg} / \mathrm{g}$ in OC contents or $10 \mathrm{mg} / \mathrm{g}$ in EC contents in particles will lead to an average increase of $4 \%-18 \%$ or $5 \%-23 \%$ in the bioaccessibility, suggesting BC likely plays a more important role. 


\section{Conclusion}

This study is an attempt to explore the potential influence of particle carbonaceous materials and particle size on the oral and inhalation bioavailability of HOCs. The results indicate a robust influence of OC and $\mathrm{EC}$ on the bioavailability in fine particles rather than coarse particles. Relatively, particle size is a less important factor for airborne particles. Furthermore, the influence of carbonaceous materials depends on physicochemical properties or emission sources of the compounds. The present study has a limitation in the small sample size. The limitation that only two particle sizes involved leads to failure to examine the effect of particle size on inhalation bioaccessibility. This study warrants further research to address the underlying mechanisms for the effects.

\section{Declarations}

\section{Ethics approval and consent to participate:}

Not applicable.

\section{Consent for publication:}

Not applicable.

\section{Availability of data and materials:}

All data generated or analyzed during this study are included in this published article and its supplementary information files.

\section{Competing interests:}

The authors declare that they have no competing interests.

\section{Funding:}

This study was financially supported by the National Key R\&D Program of China (2017YFC0212000), the Guangzhou Science and Technology Program (No. 201707020033), the National Science Foundation of China (Nos. 41771530 and 41573088), the Guangdong Foundation for Program of Science and Technology Research (No. 2017B030314057), and the State Key Laboratory of Organic Geochemistry, GIGCAS (NO. SKLOG202001).

\section{Author contributions:}

All authors contributed to the study conception and design. Investigation, writing - original draft, formal analysis and methodology: YZ; Conceptualization, writing - review \& editing and supervision: SJC; Investigation: YF and QQL; Supervision: BXM. All authors read and approved the final manuscript. 
Acknowledgements:

The authors thank Jia-Cheng Li from South China Normal University for his help in the field work and the reviewers for their valuable comments and suggestions.

\section{References}

Castro-Jimenez J, Gonzalez-Gaya B, Pizarro M, Casal P, Pizarro-Alvarez C, Dachs J (2016) Organophosphate ester flame retardants and plasticizers in the global oceanic atmosphere. Environ Sci Technol 50:12831-12839. https://doi.org/10.1021/acs.est.6b04344

Cui XY, Xiang P, He RW, Juhasz A, Ma LQ (2016) Advances in in vitro methods to evaluate oral bioaccessibility of PAHs and PBDEs in environmental matrices. Chemosphere 150:378-389. https://doi.org/10.1016/j.chemosphere.2016.02.041

Doherty BT, Hammel SC, Daniels JL, Stapleton HM, Hoffman K (2019) Organophosphate esters: Are these flame retardants and plasticizers affecting children's health? Curr Environ Health Rep 6:201-213. https://doi.org/10.1007/s40572-019-00258-0

Duan L, Palanisami T, Liu Y, Dong Z, Mallavarapu M, Kuchel T, Semple KT, Naidu R (2014) Effects of ageing and soil properties on the oral bioavailability of benzo[a]pyrene using a swine model. Environ Int 70:192-202. https://doi.org/10.1016/j.envint.2014.05.017

Fang ML, Stapleton HM (2014) Evaluating the bioaccessibility of flame retardants in house dust using an In vitro Tenax bead-assisted sorptive physiologically based method. Environ Sci Technol 48:1332313330. https://doi.org/10.1021/es503918m

Gao P, Hu J, Song J, Chen X, Ou C, Wang H, Sha C, Hang J, Xing B (2019) Inhalation bioaccessibility of polycyclic aromatic hydrocarbons in heavy PM2.5 pollution days: Implications for public health risk assessment in northern China. Environ Pollut 255:113296. https://doi.org/10.1016/j.envpol.2019.113296

Guney M, Chapuis RP, Zagury GJ (2016) Lung bioaccessibility of contaminants in particulate matter of geological origin. Environ Sci Pollut R 23:1-13. https://doi.org/10.1007/s11356-016-6623-3

Guo TF, Lin T, Li YY, Wu ZL, Jiang YQ, Guo ZG (2019) Occurrence, gas-particle partitioning, and sources of polybrominated diphenyl ethers in the atmosphere over the Yangtze River Estuary, East China Sea. Sci Total Environ 693. https://doi.org/10.1016/j.scitotenv.2019.07.344

He RW, Li YZ, Xiang P, Li C, Cui XY, Ma LQ (2018) Impact of particle size on distribution and human exposure of flame retardants in indoor dust. Environ Res 162:166-172.

https://doi.org/10.1016/j.envres.2017.12.014

He RW, Li YZ, Xiang P, Li C, Zhou CY, Zhang SJ, Cui XY, Ma LQ (2016) Organophosphorus flame retardants and phthalate esters in indoor dust from different microenvironments: Bioaccessibility and risk 
assessment. Chemosphere 150:528-535. https://doi.org/10.1016/j.chemosphere.2015.10.087

Hou R, Xu Y, Wang Z (2016) Review of OPFRs in animals and humans: absorption, bioaccumulation, metabolism, and internal exposure research. Chemosphere 153:78-90.

https://doi.org/10.1016/j.chemosphere.2016.03.003

Huang H, Jiang Y, Xu XY, Cao XD (2018) In vitro bioaccessibility and health risk assessment of heavy metals in atmospheric particulate matters from three different functional areas of Shanghai, China. Sci Total Environ 610:546-554. https://doi.org/10.1016/j.scitotenv.2017.08.074

Juhasz AL, Tang W, Smith E (2016) Using in vitro bioaccessibility to refine estimates of human exposure to PAHs via incidental soil ingestion. Environ Res 145:145-153.

https://doi.org/10.1016/j.envres.2015.12.001

Kademoglou K, Giovanoulis G, Palm Cousins A, Padilla Sanchez JA, Magner J, de Wit CA, Collin CD (2018) In vitro inhalation bioaccessibility of phthalate esters and alternative plasticizers present in indoor dust using artificial lung fluids. Environ Sci Tech Let 5:329-334.

https://doi.org/10.1021/acs.estlett.8b00113

Kang Y, Man YB, Cheung KC, Wong MH (2012) Risk assessment of human exposure to bioaccessible phthalate esters via indoor dust around the Pearl River Delta. Environ Sci Technol 46:8422-8430. https://doi.org/10.1021/es300379v

Kao CC, Chen CC, Avelino JL, Cortez MsP, Tayo LL, Lin YH, Tsai MH, Lin CW, Hsu YC, Hsieh LT (2019) Infants' neurodevelopmental effects of PM2.5 and persistent organohalogen pollutants exposure in southern Taiwan. Aerosol Air Qual Res 19:2793-2803. https://doi.org/10.4209/aaqr.2019.10.0550

Kim KH, Kabir E, Kabir S (2015) A review on the human health impact of airborne particulate matter. Environ Int 74:136-143. https://doi.org/10.1016/j.envint.2014.10.005

La Guardia MJ, Hale RC (2015) Halogenated flame-retardant concentrations in settled dust, respirable and inhalable particulates and polyurethane foam at gymnastic training facilities and residences. Environ Int 79:106-114. https://doi.org/10.1016/j.envint.2015.02.014

Li WH, Wang Y, Kannan K (2019a) Occurrence, distribution and human exposure to 20 organophosphate esters in air, soil, pine needles, river water, and dust samples collected around an airport in New York state, United States. Environ Int 131:105054. https://doi.org/10.1016/j.envint.2019.105054

Li Y, Juhasz AL, Ma LQ, Cui X (2019b) Inhalation bioaccessibility of PAHs in PM2.5: Implications for risk assessment and toxicity prediction. Sci Total Environ 650:56-64.

https://doi.org/10.1016/j.scitotenv.2018.08.246

Liu R, He R, Cui X, Ma LQ (2018) Impact of particle size on distribution, bioaccessibility, and cytotoxicity of polycyclic aromatic hydrocarbons in indoor dust. J Hazard Mater 357:341-347. 
Liu X, Ji R, Shi Y, Wang F, Chen W (2019) Release of polycyclic aromatic hydrocarbons from biochar fine particles in simulated lung fluids: Implications for bioavailability and risks of airborne aromatics. Sci Total Environ 655:1159-1168. https://doi.org/10.1016/j.scitotenv.2018.11.294

Lohmann R, Lammel G (2004) Adsorptive and absorptive contributions to the gas-particle partitioning of polycyclic aromatic hydrocarbons: State of knowledge and recommended parametrization for modeling. Environ Sci Technol 38:3793-3803. https://doi.org/10.1021/es035337q

Marcoccia M, Ronci L, De Matthaeis E, Setini A, Perrino C, Canepari S (2017) In-vivo assesment of the genotoxic and oxidative stress effects of particulate matter on Echinogammarus veneris. Chemosphere 173:124-134. https://doi.org/10.1016/j.chemosphere.2017.01.019

Niu J, Rasmussen PE, Hassan NM, Vincent R (2010) Concentration distribution and bioaccessibility of trace elements in nano and fine urban airborne particulate matter: Influence of particle size. Water Air Soil Poll 213:211-225. https://doi.org/10.1007/s11270-010-0379-z

Oleszczuk P, Godlewska P, Reible DD, Kraska P (2017) Bioaccessibility of polycyclic aromatic hydrocarbons in activated carbon or biochar amended vegetated (Salix viminalis) soil. Environ Pollut 227:406-413. https://doi.org/10.1016/j.envpol.2017.04.064

Peterson BS, Rauh VA, Bansal R, Hao X, Toth Z, Nati G, Walsh K, Miller RL, Arias F, Semanek D (2015) Effects of prenatal exposure to air pollutants (polycyclic aromatic hydrocarbons) on the development of brain white matter, cognition, and behavior in later childhood. Jama Psychiat 72:531-540. https://doi.org/10.1001/jamapsychiatry.2015.57

Polachova A, Gramblicka T, Parizek O, Sram RJ, Stupak M, Hajslova J, Pulkrabova J (2020) Estimation of human exposure to polycyclic aromatic hydrocarbons (PAHs) based on the dietary and outdoor atmospheric monitoring in the Czech Republic. Environ Res 182. https://doi.org/10.1016/j.envres.2019.108977

Raffy G, Mercier F, Glorennec P, Mandin C, Le Bot B (2018) Oral bioaccessibility of semi-volatile organic compounds (SVOCs) in settled dust: A review of measurement methods, data and influencing factors. $J$ Hazard Mater 352:215-227. https://doi.org/10.1016/j.jhazmat.2018.03.035

Rajagopalan S, Al Kindi SG, Brook RD (2018) Air pollution and cardiovascular disease JACC state-of-theart review. J Am Coll Cardiol 72:2054-2070. https://doi.org/10.1016/j.jacc.2018.07.099

Ruby MV, Lowney YW, Bunge AL, Roberts SM, Gomez Eyles JL, Ghosh U, Kissel JC, Tomlinson P, Menzie C (2016) Oral bioavailability, bioaccessibility, and dermal absorption of PAHs from soil-state of the science. Environ Sci Technol 50:2151-2164. https://doi.org/10.1021/acs.est.5b04110 
Salgueiro Gonzalez N, De Alda ML, Muniategui Lorenzo S, Prada Rodriguez D, Barcelo D (2015) Analysis and occurrence of endocrine-disrupting chemicals in airborne particles. Trac-Trends Anal Chem 66:45-52. https://doi.org/10.1016/j.trac.2014.11.006

Samara C, Voutsa D, Kouras A, Eleftheriadis K, Maggos T, Saraga D, Petrakakis M (2014) Organic and elemental carbon associated to PM10 and PM2.5 at urban sites of northern Greece. Environ Sci Pollut R 21:1769-1785. https://doi.org/10.1007/s11356-013-2052-8

Semple KT, Riding MJ, McAllister LE, Sopena Vazquez F, Bending GD (2013) Impact of black carbon on the bioaccessibility of organic contaminants in soil. J Hazard Mater 261:808-816.

https://doi.org/10.1016/j.jhazmat.2013.03.032

Shen H, Li W, Graham SE, Starr JM (2019) The role of soil and house dust physicochemical properties in determining the post ingestion bioaccessibility of sorbed polychlorinated biphenyls. Chemosphere 217:18. https://doi.org/10.1016/j.chemosphere.2018.10.195

Siciliano SD, Laird B, Lemieux C (2010) Polycyclic aromatic hydrocarbons are enriched but bioaccessibility reduced in brownfield soils adhered to human hands. Chemosphere 80:1101-1108. https://doi.org/10.1016/j.chemosphere.2010.04.061

Sofowote UM, McCarry BE, Marvin CH (2008) Source apportionment of PAH in Hamilton Harbour suspended sediments: Comparison of two factor analysis methods. Environ Sci Technol 42:6007-6014. https://doi.org/10.1021/es800219z

Sun SJ, Jia LR, Li B, Yuan AN, Kong LJ, Qi H, Ma WL, Zhang AP, Wu YN (2018) The occurrence and fate of PAHs over multiple years in a wastewater treatment plant of Harbin, Northeast China. Sci Total Environ 624:491-498. https://doi.org/10.1016/j.scitotenv.2017.12.029

Thorsen WA, Cope WG, Shea D (2004) Bioavailability of PAHs: Effects of soot carbon and PAH source. Environ Sci Technol 38:2029-2037. https://doi.org/10.1021/es0306056

Wang C, Wu S, Zhou S, Wang H, Li B, Chen H, Yu Y, Shi Y (2015) Polycyclic aromatic hydrocarbons in soils from urban to rural areas in Nanjing: Concentration, source, spatial distribution, and potential human health risk. Sci Total Environ 527-528:375-383. https://doi.org/10.1016/j.scitotenv.2015.05.025

Wang J, Chen SJ, Tian M, Zheng XB, Gonzales L, Ohura T, Mai BX, Simonich SLM (2012) Inhalation cancer risk associated with exposure to complex polycyclic aromatic hydrocarbon mixtures in an electronic waste and urban area in South China. Environ Sci Technol 46:9745-9752. https://doi.org/10.1021/es302272a

Wang W, Wu FY, Huang MJ, Kang Y, Cheung KC, Wong MH (2013a) Size fraction effect on phthalate esters accumulation, bioaccessibility and in vitro cytotoxicity of indoor/outdoor dust, and risk 
assessment of human exposure. J Hazard Mater 261:753-762.

https://doi.org/10.1016/j.jhazmat.2013.04.039

Wang W, Wu FY, Zheng JS, Wong MH (2013b) Risk assessments of PAHs and Hg exposure via settled house dust and street dust, linking with their correlations in human hair. J Hazard Mater 263:627-637. https://doi.org/10.1016/j.jhazmat.2013.10.023

Wang X, Zhu QQ, Yan XT, Wang YW, Liao CY, Jiang GB (2020) A review of organophosphate flame retardants and plasticizers in the environment: Analysis, occurrence and risk assessment. Sci Total Environ 731:139071. https://doi.org/10.1016/j.scitotenv.2020.139071

Werner D, Hale SE, Ghosh U, Luthy RG (2010) Polychlorinated biphenyl sorption and availability in fieldcontaminated sediments. Environ Sci Technol 44:2809-2815. https://doi.org/10.1021/es902325t

Yu YX, Jiang ZA, Zhao ZS, Chong D, Li GY, Ma ST, Zhang YN, An TC (2018) Novel in vitro method for measuring the mass fraction of bioaccessible atmospheric polycyclic aromatic hydrocarbons using simulated human lung fluids. Environ Pollut 242:1633-1641.

https://doi.org/10.1016/j.envpol.2018.07.114

Yu YX, Yang D, Wang XX, Huang NB, Zhang XY, Zhang DP, Fu JM (2013) Factors influencing on the bioaccessibility of polybrominated diphenyl ethers in size-specific dust from air conditioner filters. Chemosphere 93:2603-2611. https://doi.org/10.1016/j.chemosphere.2013.09.085

Zeng Y, Fan Y, Yan X, Zheng J, Chen SJ, Mai BX (2019) In vitro oral and inhalation bioaccessibility of hydrophobic organic contaminants (HOCs) in airborne particles and influence of relevant parameters. Environ Res 170:134-140. https://doi.org/10.1016/j.envres.2018.12.025

Zhang YY, Pignatello JJ, Tao S, Xing BS (2015) Bioaccessibility of PAHs in fuel soot assessed by an in vitro digestive model with absorptive sink: Effect of food ingestion. Environ Sci Technol 49:14641-14648. https://doi.org/10.1021/acs.est.5b04342

\section{Figures}



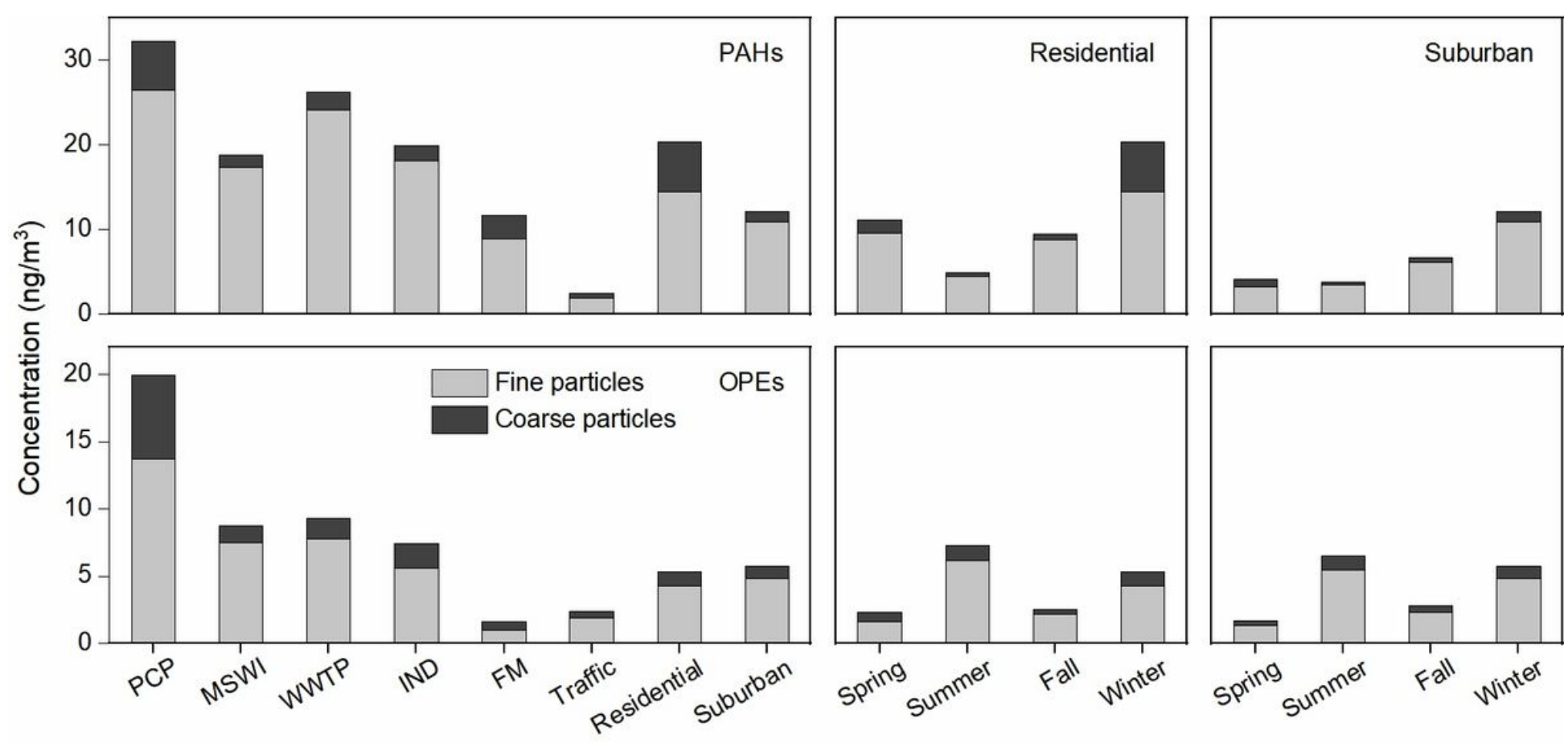

\section{Sampling site/season}

\section{Figure 1}

Spatial and temporal concentrations of HOCs in fine and coarse particles. 

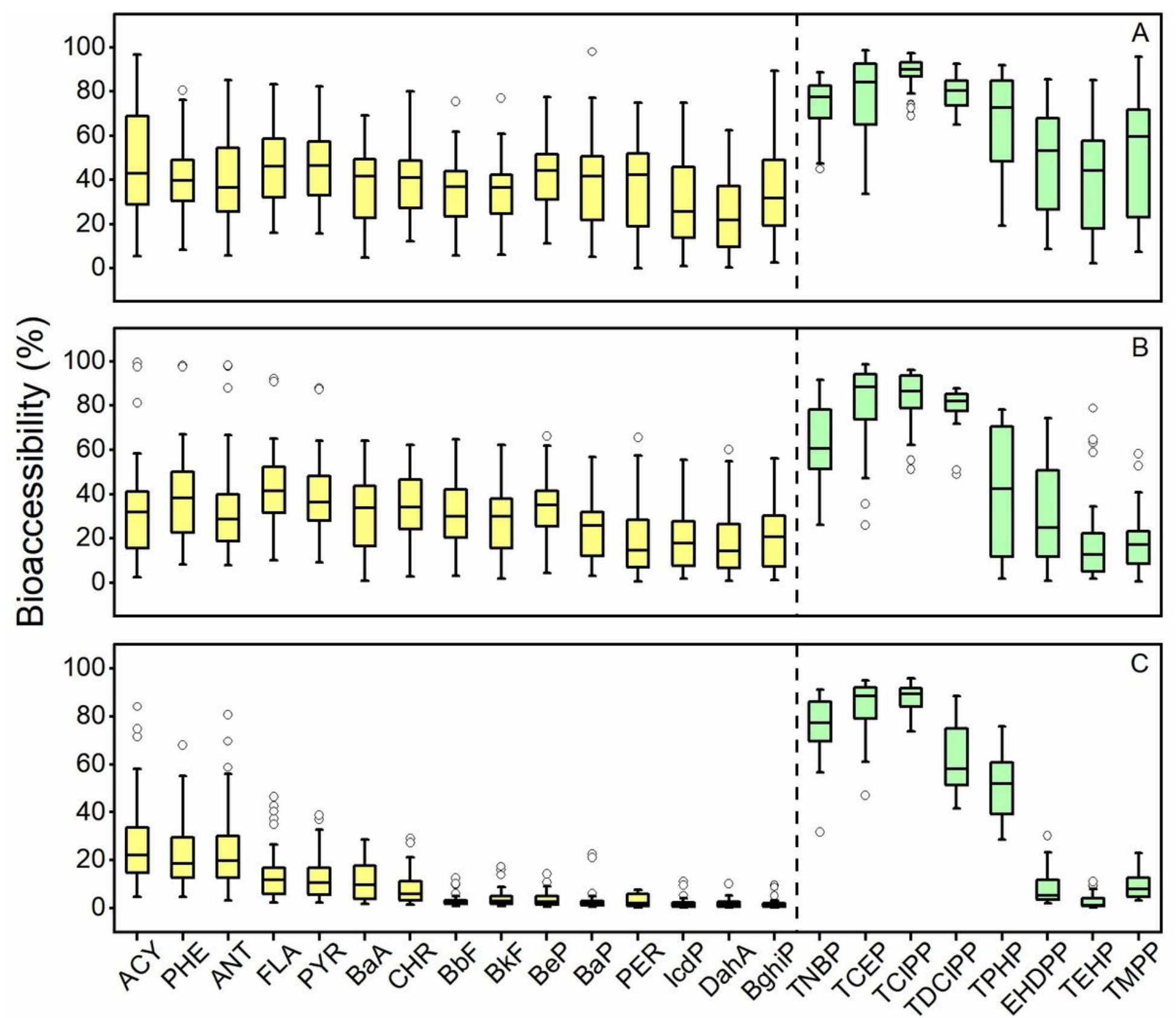

Figure 2

Oral bioaccessibility of PAHs and OPEs in fine particles (A) and coarse particles (B) and their inhalation bioaccessibility in fine particles (C). Full names of the individual PAHs and OPEs are given in Supplementary Information (HOC analysis).

\section{Supplementary Files}

This is a list of supplementary files associated with this preprint. Click to download.

- SupplementaryInformation.docx 